\title{
Social media adoption among lecturers at a traditional university in Eastern Cape Province of South Africa
}

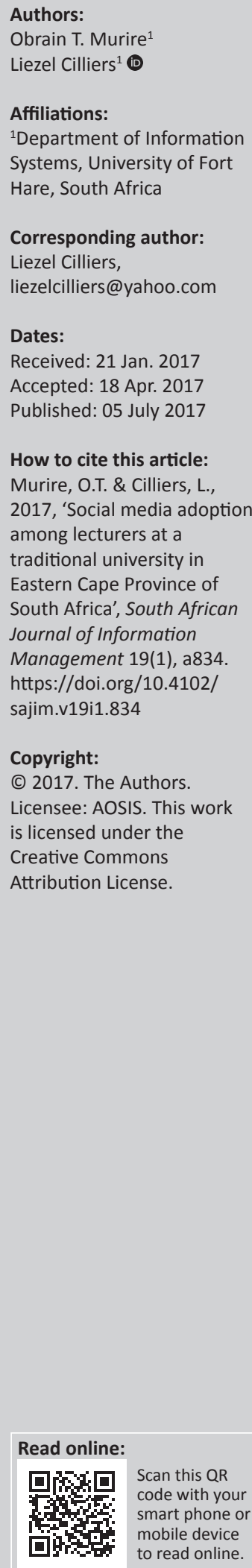

Background: There is shortage of critical skills in the South African economy. One of the reasons for this shortage is that many students at traditional universities are not completing their degree within the prescribed time frame. The massification of education at traditional universities compounds this problem as there is a decrease in the interaction between lecturers and students. Information and communication technologies, and specifically social media, have been identified as a possible solution to aid traditional universities to improve their throughput rate. Social media has become an essential tool to increase student-lecturer interaction, collaboration and communication in academic setting.

Objective: The purpose of the study was to examine social media adoption among lecturers at a traditional university in Eastern Cape Province of South Africa.

Method: The unified theory of acceptance and use of technology (UTAUT) framework was used as the theoretical foundation of the questionnaire that was distributed to 300 full-time staff members. A response rate of $39 \%$ was attained. Factor analysis was used to test the relationship between variables.

Contribution: The study's contribution is to the theoretical body of knowledge that affirms that the UTAUT framework is an appropriate tool to use to test adoption of social media at traditional universities.

Conclusion: The findings indicated that academics are conversant with emerging technologies and could incorporate these technologies into academic settings with an aim to increase communication and interaction among lecturers and learners. The results revealed that performance expectancy, social influence, effort expectancy and behavioural intention have a positive influence on social media adoption and continued use by academics in teaching and learning at traditional university. The facilitating condition scale was not statistically significant, but must be considered by management in order to improve the adoption of social media among lecturers.

\section{Introduction}

Studies revealed that there is a shortage of critical skills in the South African economy (Breier \& Mabizela 2008; Strydom, Mentz \& Kuh 2010). This scarcity of critical skills has impacted negatively on the equity of the South African workforce (Mohamedbhai 2014; Teferra 2014). One of the reasons to blame for this shortage of critical skills in the workforce is that traditional universities in South Africa are not producing enough quality graduates. Fifty-five percent of first-year students will not graduate, whereas only $5 \%$ of the enrolled non-white students will finish their undergraduate degrees in the prescribed time (Higher Education South Africa 2015; Zulu 2011). One of the reasons attributed for this dismal performance is massification, which has severely impacted the throughput rate of traditional universities. Prosser and Trigwell (2013) reveal that large classes and poor academic literacy of students are affecting the quality of education as they reduce student-lecturer interaction (Breier \& Mabizela 2008; Council on Higher Education 2013; Mohamedbhai 2008; Strydom et al. 2010). To solve the challenge of massification, traditional universities need to identify new solutions, such as emerging technologies, to improve the throughput rate in order to address critical skills shortage in the South African economy.

Information and communication technologies (ICTs) have been identified as a possible solution that can be used to facilitate effective communication among students and lecturers and thus has the potential to increase throughput rate and student pass rates (Nurulrabihah et al. 2013; Renes \& Strange 2011). Perron et al. (2010) define ICTs as: 
technologies used to convey, manipulate and store data by electronic means. This can include e-mail, Whatsapp, video chat (e.g. Skype) and online social media (e.g. Facebook). It also includes all the different computing devices (e.g. laptop computers and smart phones) that carry out a wide range of communication and information functions. (p. 67)

Mobile technology has become a preferred mode of communication for young adults (Robinson 2014). A recent study suggested that university students are the most active mobile phone users with the functions most often used including text messaging, gaming and the Internet (Cilliers 2016). Given the popularity of mobile communication among this age group, the potential to use social media to improve academic activities at higher education institutions is immense (Robinson 2014). Despite the potential benefit of social media in teaching activities, the technology has not been widely adopted by lecturers at traditional universities in South Africa (Bingimlas 2009; Nakamaru 2011; Nurulrabihah et al. 2013). The purpose of this article is to investigate what factors will determine the adoption of social media among lecturers at a traditional university in South Africa.

The article is outlined as follows: The first section introduces ICTs in higher education, with a specific emphasis on social media that can be used for teaching and learning. This is followed by a discussion of the quantitative survey methodology used in this study to collect data followed by the theoretical and empirical discussion of the unified theory of acceptance and use of technology (UTAUT) model. The results and contribution of the article are next followed by the conclusion of the article.

\section{Information and communication technologies in higher education}

According to Liu and Hwang (2010), the advent of ICT has precipitated various changes in the teaching and learning environment. Traditional universities are putting ICT strategies in place in order to benefit from the integrating of technology in academic setting (Teferra 2014). When social media is combined by relevant content and services, it can help to improve the interaction and communication between students and lecturers at traditional universities (Almeshal 2015).

Traditional universities are adopting a variety of tools to foster effective learning of students and improve teaching and learning methods. These tools include learning management systems, smartboards and e-learning. However, because of the cost of these tools, numerous traditional universities have been investigating the usefulness of emerging tools in transforming academic activities (Almeshal 2015). Studies reveal that the integration of emerging technologies, such as social media, in academic activities may assist students' critical thinking skills and also improve self-concept and motivation (Strydom et al. 2010; Teferra 2014). Furthermore, social media improves the interaction and collaboration between students and lecturers, which will be difficult to attain without the aid of social media tools (CHE 2007; Hew \& Brush 2007).

\section{Social media in higher education}

Shullich (2011) describes social media as websites and applications that allow lecturers to create and share content. Social media tools include Facebook, Twitter, MySpace, Flickr, Google Plus and YouTube. Special interest forums, blogs and user communities can also be considered to fall in this category (Batikas et al. 2013). Furthermore, Shullich (2011) states that social media plays a significant role in stimulating interaction among students as well as lecturers.

Most of the student population enrolled at higher education institutions are using social media (Almeshal 2015). Therefore, traditional universities ought to incorporate social networking tools that support individual learning and student-centred education spaces. This is supported by Gonzalez (2010) who asserts that the integration of social media in the traditional university academic environment has increased during the last decade. Bingimlas (2009) mentions that the rapid growth of social media plays an essential role in teaching and learning processes in higher education systems. Many traditional universities have integrated these technologies in their teaching and learning environments. For this reason, social media adoption can be used to do old activities in new ways in academic field.

\section{Benefits of social media in academic setting}

The University of Glasgow (2013) states that Web 2.0 technologies provide a new paradigm to improve the academic environment. A number of studies perceive social media as a means to promote more student-centred learning (Almeshal 2015; Asma 2012; Chen \& Bryer 2012). Social constructivist pedagogies are developed if students take part in social networks for teaching and learning. Thus, social media is a useful tool that offers a mechanism for students to assess each other in order to build an active community of practice.

Nurulrabihah et al. (2013) state that emerging technologies such as wikis, Twitter and Facebook are already available and widely adopted by students in their personal life and therefore could be used to facilitate their teaching and learning process. Incorporating social media in the academic setting will allow lecturers and learners to communicate about class work at any time which offers virtual office hours. A further benefit is that, the use of social media in academic environment can play a pivotal role of increasing student engagement through online discussions that are offered by varied technologies, for instance, blogs and wikis. Additionally, wikis can facilitate effective collaboration of students and lecturers, thereby increasing interactions. Cilliers (2016) states that wikis use a basic format language; this means that no exceptional web skills are necessary for students and lecturers to use them in academic setting. 
Emerging technologies also provides features that help to manage students and promote student-lecturer interaction that is reduced because of massification that is taking place at traditional university.

However, there are some challenges associated with integrating social media in the academic setting. These include a lack of leadership support, poor planning, and inadequate knowledge or awareness of social media's role in academic setting (Bingimlas 2009). Furthermore, if the teaching pedagogy does not support social media-orientated learning, it will not be adopted by lecturers (Schoepp 2005). Availability of resources and efficiency of the social media are common problems mentioned by lecturers for not integrating social media in their teaching practices (Govender \& Mararaj 2006).

\section{Research methodology}

A quantitative survey tool was used to collect data at one traditional university in the Eastern Cape Province of South Africa. The questionnaire was adapted from Venkatesh et al. (2003), after a thorough literature review, to test social media adoption among lecturers at the university. The questionnaire was adapted to reflect the social media context of the study. The questionnaire was piloted to 10 lecturers for suitability, user-friendliness and unambiguousness.

The study population was limited to full-time lecturers at one traditional university where data were collected. A link to the web-based questionnaire was emailed to all the full-time lecturers. The total number of lecturers was 300. The aggregate of 116 responses was received, resulting in a response rate of $39 \%$. All responses to the questionnaire were analysed as quantitative variables. Statistical Package for the Social Science (SPSS 23) was used to analyse the primary data making use of factor analysis. Cronbach's alpha scores were applied to calculate each sub-scale in order to test the reliability and consistency of the instrument.

\section{Unified theory of acceptance and use of technology}

In order to examine the adoption of social media among lecturers at a traditional university, the UTAUT framework was chosen as an appropriate theoretical framework. The UTAUT was developed from eight diverse models with the aim of enhancing the success rate of predicting if technology will be accepted in a specific context. This model was found to explain $70 \%$ of the variance in behavioural intention to use a technology and $50 \%$ of the variance in technology use (Venkatesh et al. 2003). This model is useful to explain variances in lecturers' adoption of social media tools in academic environment.

The model comprises of four key constructs: performance expectancy, effort expectancy, social influence and facilitating conditions.

\section{Performance expectancy}

This construct refers to 'the degree to which an individual believes that using the system will help him or her to attain gains in job performance' (Venkatesh et al. 2003:447). It denotes lecturers' belief that integrating social media in academic environment would be an advantage to them as well as to students.

\section{Effort expectancy}

This construct refers to 'the degree of ease associated with the use of the system' (Venkatesh et al. 2003:450). It refers to the expected amount of ease that lecturers presume while using social media to accomplish their professional goals.

\section{Social influence}

This construct refers to the degree to which an individual perceives that important others believe he or she should use the new system' (Venkatesh et al. 2003:451). It is referred as the impact of colleagues and senior management support or role played by the heads of the institution in inspiring and encouraging lecturers to employ social media in academia to facilitate curriculum delivery.

\section{Facilitating conditions}

This construct describes 'the degree to which an individual believes that an organizational and technical infrastructure exist to support use of the system' (Venkatesh et al. 2003:453). They denote the extent to which an individual believes that institutional and technical infrastructure exists to support the use of social media (Venkatesh et al. 2003). This involves training of lecturers, hands-on user and physical infrastructure support, as well as expert solutions to lecturers' queries. Various studies in information systems have validated the UTAUT as it is used in different fields (Venkatesh et al. 2003).

\section{Results and discussion}

Table 1 indicates that some of the participants did not indicate responses, especially with regard to the biographical section.

\section{Reliability analysis}

The article applied Cronbach's alpha to test reliability. Table 2 shows that four of the five scales of the UTAUT construct attained a good degree of reliability as each was computed above 0.70 (Marchewka, Liu \& Kostiwa 2007).

The Cronbach's alpha for facilitating condition construct was the lowest at 0.542 . Efforts to increase the facilitation condition reliability scale did not yield clearly enhanced results. Conversely, because of the fact that 'facilitating condition' occupies a pivotal role in the UTAUT theory and as an independent variable in this study, a decision was made to retain the scale in its current form and continue with a factor analysis to test the validity. 
TABLE 1: Demographic details of participants.

\begin{tabular}{llll}
\hline Item & Category & Frequency & $\mathbf{\%}$ \\
\hline Gender & Male & 58 & 45.8 \\
& Female & 104 & 54.2 \\
& $<30$ & 9 & 10.8 \\
& $30-40$ & 29 & 34.9 \\
& $41-50$ & 33 & 39.8 \\
Length in & $>50$ & 12 & 14.5 \\
academia & $<3$ & 13 & 15.7 \\
& $3-6$ & 27 & 32.50 \\
& $7-10$ & 13 & 15.70 \\
& $11-14$ & 14 & 16.90 \\
& $15+$ & 15 & 18.0 \\
& Did not indicate* & 1 & 1.2 \\
Use of & Daily & 15 & 18.1 \\
social media & Once a week & 6 & 7.2 \\
& Once a month & 15 & 18.1 \\
& Occasionally (when I cannot avoid it) & 28 & 33.7 \\
& Never & 19 & 22.9 \\
\hline
\end{tabular}

TABLE 2: Empirical reliability of data collection instrument.

\begin{tabular}{lcc}
\hline Scale & Number of Items & Cronbach's alpha $(\alpha)$ \\
\hline 1: Performance expectancy & 3 & 0.833 \\
2: Effort expectancy & 3 & 0.869 \\
3: Social influence & 3 & 0.831 \\
4: Facilitating condition & 4 & 0.542 \\
5: Behavioural intention & 3 & 0.956 \\
\hline
\end{tabular}

The data were considered suitable for factor analysis based on the results from the Kaiser-Meyer-Olkin (KMO) measure of sampling competence (Kaiser 1970, 1974). Validity of the constructs and relevant scales was tested using both exploratory and confirmatory factor analyses. Directionality of relationships was established by regression analysis. Table 3 provides summary statistics of counts, percentages and distribution of measures at factor level on a Varimax rotated component matrix. Some of the items were removed from the variables with the aim to achieve this factor analysis result.

The behavioural intention scale was reduced from five to four items; for social influence, effort expectancy, performance expectancy as well as facilitating condition items were also reduced to three from four items. Empirical reliability was then re-checked in order to ensure that satisfactory Cronbach's alpha was achieved. Overall reliability and validity for these variables can be considered to be satisfactory as per the acclaimed inception 0.7 (Nunnally 1978).

The third question in the facilitating condition scale, 'Using social media for teaching and learning is not compatible with other lecturing responsibilities that I have', loaded on the behavioural intent factor with a negative relationship (-0.751). A possible explanation for this could be that using social media in academic setting does not require much training of lecturers, as they are already using the technology, availability of social media on smart phone devices, and there is adequate physical ICT infrastructure support.

Regarding the behavioural intention, the majority of lecturers are positive that they will incorporate emerging technologies in their teaching and learning activities in the near future.
TABLE 3: Varimax rotated component matrix.

\begin{tabular}{llllll}
\hline Variable & $\begin{array}{l}\text { Behavioural } \\
\text { intention }\end{array}$ & $\begin{array}{l}\text { Social } \\
\text { influence }\end{array}$ & $\begin{array}{l}\text { Effort } \\
\text { expectancy }\end{array}$ & $\begin{array}{l}\text { Performance } \\
\text { expectancy }\end{array}$ & $\begin{array}{l}\text { Facilitating } \\
\text { condition }\end{array}$ \\
\hline BI1 & 0.723 & - & - & - & - \\
BI2 & 0.659 & - & - & - & - \\
BI3 & 0.658 & - & - & - & - \\
SI1 & - & 0.899 & - & - & - \\
SI2 & - & 0.788 & - & - & - \\
SI3 & - & 0.782 & - & - & - \\
EE1 & - & - & 0.869 & - & - \\
EE2 & - & - & 0.825 & - & - \\
EE3 & - & - & 0.700 & - & - \\
PE1 & - & - & - & 0.913 & - \\
PE2 & - & - & - & 0.815 & - \\
PE3 & - & - & - & 0.807 & - \\
FC1 & - & - & - & - & 0.858 \\
FC2 & - & - & 0.54 & - & 0.586 \\
FC3 & -0.751 & - & - & - & 0.526 \\
FC4 & - & 0.428 & - & - & 0.526 \\
\hline
\end{tabular}

$\mathrm{BI}$, behavioural intention; $\mathrm{SI}$, social influence; $\mathrm{EE}$, effort expectancy; $\mathrm{PE}$, performance expectancy; $\mathrm{FC}$, facilitating condition

The results show that lecturers are likely to adopt emerging technologies based on the findings of the study. Thus, the usage of social media is interrelated with constructs found in the UTAUT model.

Likewise, $71.1 \%$ of the lecturers expect to use social media in teaching and learning in the next 12 months. Furthermore, a majority of the lecturers $(75.9 \%)$ plan to use social media in academia in the next 12 months. This is because they find social media to be a useful tool, and most of the lecturers are knowledgeable about social media. There is a need for management support in order for the lecturers to adopt social media in the near future. The incorporation which is a taking place depends on individual lecturer effort.

Table 4 reveals how the variables in the model contribute to the prediction of the intention to use social media in academic setting. It indicates that the beta value for social influence is 0.391 making it the largest contributor to the model, and thus, it is the largest predictor of behaviour intention to use emerging technologies for teaching and learning purposes. Performance expectancy is the second highest predictor of intention to use with a beta coefficient of 0.308 , whereas effort expectancy and facilitating condition occupy position three and four, respectively, with beta values of 0.232 and -0.035 . With respect to significance of these relationships, all four predictor variables can be considered to be making statistically significant contributions to the equation $(p<0.05)$.

\section{Ethical considerations}

Ethical clearance was applied for and received from the Universities Research Ethics Committee to conduct the study.

\section{Discussion}

The article investigated lecturers' adoption of social media at a traditional university as it improves communication, collaboration as well increased student and lecturer interaction. 
TABLE 4: Model summary.

\begin{tabular}{|c|c|c|c|c|c|}
\hline \multirow[t]{2}{*}{ Coefficients model } & \multicolumn{2}{|c|}{ Unstandardised coefficients } & \multirow[t]{2}{*}{ Standardised coefficients (Beta) } & \multirow[t]{2}{*}{$t$} & \multirow[t]{2}{*}{ Significance } \\
\hline & $\boldsymbol{B}$ & Standard error & & & \\
\hline Constant & 1.913 & 0.853 & - & 2.243 & 0.028 \\
\hline Social influence & 0.340 & 0.084 & 0.391 & 4.037 & 0.000 \\
\hline Effort expectancy & 0.197 & 0.095 & 0.232 & 2.068 & 0.042 \\
\hline Facilitating conditions & -0.043 & 0.138 & -0.035 & -0.310 & 0.758 \\
\hline Performance expectancy & 0.357 & 0.110 & 0.308 & 3.256 & 0.002 \\
\hline
\end{tabular}

The receptivity of academics to use emerging technologies in the teaching and learning environment was examined by applying variables of the UTAUT model (Davis 1989). The article concurs with preceding literature on the subject of the strong predictive power of UTAUT model. Furthermore, the study also reveals the popularity of social media among the students and the lecturers (Robinson 2014).

The results indicated that social influence has a beta value of 0.391 making it the largest contributor to the UTAUT model. A possible reason for this could be that academics, senior management and department of higher education need to support lecturers to use emerging technologies for teaching and learning purposes.

Performance expectancy is statistically significant, and it ranks the second highest predictor of intention to use with a beta coefficient of 0.308 ; a possible reason for this could be that lecturers feel that social media supports teaching and learning, and it enhances their productivity as well as enabling them to collaborate and communicate with students.

Effort expectancy is statistically significant, occupies position three with a beta value of 0.232 and was found to be statistically significant. The results indicate that adopting social media in academic setting is easy, clear and understandable, and academics are already skilful making use of social media in their private lives, and can transfer these skills to the teaching and learning environment. The results indicated that lecturers want to adopt social media in future.

Facilitating condition is not statistically significant and has a beta value -0.035 . The results indicated negative relationship (-0.751) on a question 'Using social media for teaching and learning is not compatible with other lecturing responsibilities that I have'. The reason advanced is that some of the courses cannot be taught on social media, but lecturers can employ these emerging tools in academic setting for communication purposes. This assist in increasing student and lecturer interaction reduced by massification of teaching and learning at higher education in South Africa.

Additionally, a moderate relationship was found on facilitating condition with 0.54 and 0.428 . The results show that the question 'I have the knowledge necessary to use social media for teaching and learning', 'There is a specific person allocated for assistance if I experience difficulties when using social media for teaching and learning' is not significant. A possible reason could be that the Internet and help desk is already in place at the university but it is one of the construct that should be considered.

\section{Practical implications}

\section{Contribution}

The study's contribution is to the theoretical body of knowledge that affirms that the UTAUT framework is an appropriate tool to use to test adoption of ICT at traditional universities and that traditional university management has a duty to reinforce the use of emerging technologies by lecturers to improve student-lecturer interaction and communication and promote collaborative learning among students in order to improve the throughput rate.

\section{Limitations}

One of the constraints to the study is that data were collected from one traditional university. This means that the results cannot be generalised to all traditional universities in South Africa, but is only applicable to the university used in this study. Future research could broaden the study population to all traditional universities in the country. The sample size was small. Additionally, a survey method was employed in the study; therefore, the results are only based on quantitative data, and thus, there was no follow-up with qualitative interviews. Future research on adoption of social media in the teaching and learning environment in South Africa must draw a comprehensive sample including at least one traditional university from each province in South Africa. There is need to investigate the influence of Internet and change management theories towards the adoption of social media in teaching and learning at higher education institutions in South Africa.

\section{Conclusion}

The findings indicated that academics are conversant with emerging technologies and they could incorporate them in academic setting with an aim to increase communication and interaction among lecturers and learners. The results reveal that performance expectancy, social influence, effort expectancy and behavioural intention have a positive influence on social media adoption and continued use by academics in teaching and learning at a traditional university. The facilitating condition scale was not statistically significant, but must be considered by management in order to improve the adoption of social media among lecturers. Lecturers were positive that they will adopt social media in their teaching and learning activities in the near future. Some lecturers expect to employ social media in academia in the next 12 months. 
Therefore, social media is an essential tool in teaching and learning and could be used by lecturers as a tool to improve pass rates in order to address the critical skills shortage in the economy.

\section{Acknowledgements Competing interests}

The authors declare that they have no financial or personal relationships that may have inappropriately influenced them in writing this article.

\section{Authors' contributions}

O.M. completed the research study in fulfilment of her degree. L.C. made conceptual contributions to the project.

\section{References}

Almeshal, T., 2015, 'Social media adoption in learning and teaching by higher education faculty', in 9th International Technology, Education and Development Conference, Higher Education Faculty, Madrid, 2-4th March, pp. 1-10.

Asma, F., 2012, The advantages and disadvantages of technology in the classroom viewed 06 July 2016, from https://sites.google.com/site/technoeducom/advdisadv

Batikas, M., Bavel, R., Martin, A. \& Maghiros, I., 2013, Use of social media by European SMEs, viewed 01 July 2016, from http://www.europski-fondovi.eu/sites/default/ files/dokumenti/KK0113565ENN_002.pdf

Bingimlas, K.A., 2009, 'Barriers to the successful integration of ICT in teaching and learning environments: A review of the literature', Eurasia Journal of Mathematics, Science \& Technology Education 5, 235-245.

Breier, M. \& Mabizela, M., 2008, Higher education, Kraak A. \& Press K, Pretoria.

CHE, 2007, Review of higher education in South Africa, The Council on Higher Education, Pretoria.

Chen, B. \& Bryer, T., 2012, 'Investigating instructional strategies for using social media in formal and informal learning', The International Review of Research in Open and Distance Learning 13(1), 87-104.

Cilliers, L., 2016, 'Wiki acceptance by university students to improve collaboration in Higher Education', Innovations in Education and Teaching International 1-9. https://doi.org/10.1080/14703297.2016.1180255

Council on Higher Education, 2013, A proposal for under massification graduate curriculum reform in South Africa: The case for a flexible curriculum structure, $\mathrm{CHE}$, Pretoria.

Davis, F.D., 1989, 'Perceived usefulness, perceived ease of use and user acceptance of information technology', MIS Quarterly 13, 319-340.

Gonzalez, C., 2010, What do university teachers think e-learning is good for in their teaching, Routledge, London.

Govender, D.W. \& Mararaj, M.S., 2006, 'Information and communications technology integration in teaching and learning: A critical analysis', Doctoral dissertation, UKZN.
Hew, K.F. \& Brush, T., 2007, 'Integrating technology into K-12 teaching and learning: Current knowledge gaps and recommendations for future research', Educational Technology Research and Development 55(3), 223-255. https://doi.org/10.1007/ Technology Research
s11423-006-9022-5

Higher Education South Africa, 2015, 'Strategic framework for HESA', Insight 1-15. Kaiser, H., 1970, 'A second generation Little Jiffy', Psychometrika 35, 401-415. Kaiser, H., 1974, 'An index of factorial simplicity', Psychometrika 39, 31-36.

Liu, G.Z. \& Hwang, G.J., 2010, 'A key step to understand paradigm shift in e-learning: Towards context-aware ubiquitous learning', British Journal of Educational Technology 41(2), E1-E2. https://doi.org/10.1111/j.1467-8535.2009.00976.x

Marchewka, J.T., Liu, C. \& Kostiwa, K., 2007, 'An application of the UTAUT model for understanding student perceptions using course management software', Communications of the IIMA 7(2), 93-104.

Mohamedbhai, G., 2008, The effects of Massification of higher education in Africa, Association of African Universities, Ghana.

Mohamedbhai, G., 2014, 'The effects of massification of higher education in Africa', Higher Education 1(1), 1-88.

Nakamaru, S., 2011, Making (and not making) connections with Web 2.0 technology in the ESL composition classroom, National Council of Teachers of English, London.

Nunnally, J.C., 1978, Psychometric theory, McGraw-Hill, New York.

Nurulrabihah, M.N., Siti Hajar, A.R., Norlidah, A., Saedah, S., Mohd Ridhuan, M.J. \& Zaharah, H., 2013, 'Usage of facebook: The future impact of curriculum implementation on students in Malaysia', in 13th International Educationa Technology Conference, vol. 103, Kuala Lumpur, Malaysia, 13-15th March, pp. Technology

Perron, B.E., Taylor, H.O., Glass, J.E. \& Margerum-Leys, J., 2010, 'Information and communication technologies in social work', Information and Communications Technologies 11(1), 67-81.

Prosser, M. \& Trigwell, K., 2013, 'Qualitative variation in approaches to university T \& L in Large first-year classes', Higher Education 67(6), 783-795.

Renes, S. \& Strange, A.T., 2011, 'Using technology to enhance higher education', Innovative Higher Education 36(3), 203-213. https://doi.org/10.1007/s10755010-9167-3

Robinson, G., 2014, 'Why tablets are a key learning tool in special education' TabTimes, viewed 28 June 2016, from http://tabtimes.com; http://tabtimes.com/ feature/education/2014/06/09/why-tablets-are-key-learning-tool-specialeducation

Schoepp, K., 2005, 'Learning and teaching in higher education: Gulf perspectives', Higher Education 2(1), 1-26.

Shullich, R., 2011, Risk assessment of social media, SANS Institute InfoSec Reading Room, viewed 28 June 2016, from http://www.sans.org/readingroom/whitepapers/ privacy/risk-assessment-social-media-33940

Strydom, J.F., Mentz, M. \& Kuh, G.D., 2010, 'Enhancing success in higher education by measuring student engagement in South Africa', Acta Academica 42(10), 1-13.

Teferra, D., 2014, 'Charting African higher education: Perspectives at a glance', International Journal of African Higher Education 1, 1. https://doi.org/10.6017/ ijahe.v1i1.5642

University of Glasgow, 2013, Teaching in higher education: Can social media enhance the learning experience?, viewed 01 August 2015, from http://www.gla.ac.uk/ media/media_276225_en.pdf

Venkatesh, V., Morris, M., Davids, G. \& Davis, F., 2003, 'User acceptance of information technology: Toward a unified view', MIS Quarterly 27(3), 425-478.

Zulu, C., 2011, 'Empowering first year (post-matric) students in basic research skills: A strategy for education for social justice', South African Journal of Education 31(3) 447-457. https://doi.org/10.15700/saje.v31n3a546 